\title{
Role of electron-donating cosubstrates in the anaerobic biotransformation of chlorophenoxyacetates to chlorophenols by a bacterial consortium enriched on phenoxyacetate
}

\author{
Susan A. Gibson ${ }^{1} \&$ Joseph M. Suflita* \\ Department of Botany and Microbiology, University of Oklahoma, Norman, OK 73019-0245, USA \\ ${ }^{1}$ Present address: Dept of Biology \& Microbiology, South Dakota, State University, Brookings, SD 57007-2124, \\ USA (* Requests for reprints)
}

Biodegradation 4: 51-57, 1993

\section{Corrigendum}

It has been brought to our attention that an ether cleaving enzyme activity has been demonstrated in cell-free extracts from anaerobic polyethylene glycol (PEG) degrading cultures of Acetobacterium sp. (Schramm \& Schink 1991), Pelobacter venetianus and Bacteriodes strain PG1 (Frings et al, 1992). This activity was described, subsequent to the submission of our article, as a PEG-acetaldehyde lyase. As such, it is mechanistically distinct from the hydrolytic reaction we originally suggested for this bioconversion.

\section{References}

1. Frings J,Schramm E \& Schink B (1992) Enzymes involved in anaerobic polyethylene glycol degradation by Pelobacter venetianus and Bacteriodes strain PG1 Appl. Environ. Microbiol. $58: 2164-2167$,

2. Schramm E \& Schink B (1991) Ether-cleaving enzyme and diol dehydratase involved in anaerobic polyethylene glycol degradation by a new Acetobacterium sp. Biodegradation 2: 71-79. 